\title{
Catch-up Growth in Male Rats after Growth Retardation during the Suckling Period
}

\author{
J. P. G. Williams, ${ }^{[32]}$ J. M. Tanner, and P. C. R. Hughes \\ Department of Growth and Development, Institute of Child Health, University of London, London, England
}

\section{Extract}

On the day of birth pups from several dams were pooled and reallocated so that some of the dams had 8 pups while others had 16. The pups were weaned at 21 days and placed two to a cage with unlimited food and water. The pups were weighed and measured on days $3,7,14,28,35,49,63,77,91,105,119$, and 228, whole body radiographs were also taken which enabled an assessment of skeletal maturity to be made. The experiment was continued until skeletal maturity reached $98 \%$ of the adult value in both groups.

At 21 days the undernourished males were only $60 \%(P<0.001)$ of the weight of the normal males. After weaning, and hence during rehabilitation, the difference between the groups progressively diminished, the undernourished being $65 \%$ of the normals at 28 days $(P<0.001), 72 \%$ at 35 days $(P<0.001), 83 \%(P<0.001)$ at 49 days, and $90 \%(P<0.05)$ at 119 days. The ultimate difference, however, at 228 days, when bone maturity was $98 \%$ of the adult value, remained significant with undernourished $88 \%(P<0.001)$ of the normals; the catch-up was not complete. Both groups had a marked increase of velocity after weaning, rising to a peak around 55 days. During this period the undernourished still grew at an absolutely slower rate than the well nourished normals; therefore, in relation to age they did not show a catch-up in weight during this time. In relation to their body weight, however, they were growing faster than the normals; their 28-49-day rate being $19 \%$ of their weight at 28 days, compared with that of the normals, $14 \%$.

At weaning, the undernourished were only $87 \%(P<0.001)$ of the nose-rump length of the normals, and at 28 days, despite 7 days of rehabilitation, they had further decreased to $85 \%(P<0.001)$. Thereafter, their velocity equaled or exceeded that of the normals, so that by 35 days they were $90 \%(P<0.001)$ as long, by 63 days $97 \%$, and by 120 days $98 \%$ as long, with a difference that was no longer statistically significant. The velocity curves showed that a catch-up velocity occurred, but not immediately after rehabilitation commenced.

The tail length was less affected than the body length until the last part of the suckling period. However, by the time of weaning, the mean for the undernourished animals was $87 \%(P<0.001)$ of the normals. The velocity of the undernourished animals failed to increase immediately after weaning and at 28 days the mean for the undernourished animals had fallen to $80 \%(P<0.001)$ of the normals. Thereafter, the same sort of catch up occurred as for body length, although the extent was less and by the end of the growth period the undernourished animals still had significantly shorter $(P<0.05)$ tails than the normal animals, finally averaging $97 \%$.

By 14 days the skeletal maturity scores of the undernourished had fallen behind the 
normals by an amount corresponding to about a day's growth. After weaning the undernourished group fell still further behind, at 28 days being some $5(P<0.001)$ days retarded. Only after 35 days did the undernourished animals begin to overtake the normals as the latter's increments in score diminished. At weaning the normals were longer even for their maturity score. Thus the difference in size was not solely due to slowing down development in the undernourished, for if this were so the two groups would be equal in size at equal maturity scores. The two groups did become equal in weight and lengths for maturity at a score which corresponded to about 28 days in normals and 35 days in the undernourished. From 35 days to about 75 days the undernourished suffered primarily from a delay in growth, so they were in correct sizematurity proportion but delayed on their time path. However, later the normals increased their weight for given bone maturity relative to the undernourished and at the very end of the growth period did so markedly. Thus the final weight deficit of the undernourished was not due to deficit in the skeleton but in some other tissue.

At the end of growth the undernourished were only $88 \%$ of the weight of the normals, this difference being significant $(P<0.001$.) In nose-rump length they had caught up to $98 \%$ of the normals, the $2 \%$ difference not being statistically significant. In tail length they reached $97 \%$ of the normals $(P<0.05)$.

\section{Speculation}

Catch-up growth in male rats during rehabilitation after undernutrition in the suckling period is complete for some tissues but not for others. Completeness may be have been missed by previous investigators who did not follow the animals until full skeletal maturity was attained and growth had ceased.

The difference in lengths and weight between the undernourished-rehabilitated and control rats are partly, and for some ages, wholly, due to differences in maturity (the undernourished suffering from a growth delay) and not size at given maturity.

Incompleteness of the catch up in body weight is due in large part to failure of the adipose organ to develop adequately in later life. This indicates that the sensitive period, during which the size of the future adipose organ is determined, includes the
first 3 weeks of life in the rat.

\section{Introduction}

Catch-up growth is a term introduced by Prader $e t$ al. [18] to describe the increased growth velocity which occurs in children after a period of growth retardation when the cause of the retardation is removed. Catchup may be defined as a growth velocity above the statistical limits of normality for age (or alternatively, or additionally, for bone age or other measure of maturity) during a defined period of time. The effect of catch-up growth is to take the child towards or, in favorable circumstances, right onto his original preretardation growth curve. In the former case, catch-up growth may be said to be incomplete, in the latter, complete. Similar phenomena have been described in the animal experimental literature since at least 1915, when Osborne and Mendel [16] reported that during refeeding after malnutrition, rats increased in weight at a rate equal to or greater than that expected for their size. Bohman [2], describing the same occurrence in cattle given different feeding regimes at different times, used the term "compensatory growth," since the extra growth compensates for the lack of earlier growth. We prefer to use the term catch-up however, as compensatory growth had been earlier pre-empted for the growth occurring in response to loss (that is removal) of tissue (see Reference 4), as in compensatory renal hypertrophy after unilateral nephrectomy [15].

The catch-up of growth depends in part on the time of onset of the previous retardation [14, 28]. The earlier the retardation begins, the less likely it is that complete catch-up will occur, although a greater-than-normal velocity may be established for a time. If growth and maturation are slowed down equally, then the "harmony of growth" [24] is preserved and complete 
catch-up may be anticipated. This is the situation categorized diagnostically as pure growth delay in pediatric practice [23]. However, when maturation of a tissue or organ proceeds while growth in size is arrested, catch-up may be incomplete, and this tissue or organ may remain reduced relative to the rest of the animal. Winnick and Noble [27], among others, have shown how the ending of the period of cell division in an organ is critical in this respect; despite starvation, maturational processes may continue, whose passage renders impossible subsequent increase in cell number. Different organs differ in this respect, and the present study examines to what extent catch-up may occur in the lengths and the body weight of male rats whose growth has been retarded during the suckling period by moderate undernutrition. At the same time the effect on skeletal maturity has been studied so that during the retardation and catch-up periods harmonic growth delay can be distinguished from dysharmonic. It seems that the skeleton shows almost pure growth delay with complete catch-up, whereas the weight is permanently reduced. A second paper reports a similar experiment on female rats and contrasts the responses of the two sexes [26].

\section{Materials and Methods}

The animals used were random-bred black-hooded rats originally supplied by the Medical Research Council and maintained in our animal house for the last 6 years. They were kept at $20-22^{\circ}, 45-48 \%$ relative humidity, and under a 12-hr light regimen. On the day of birth the pups from several dams were pooled and reallocated so that some of the dams had 8 pups ("normal or 8-sib litters"), whereas others had 16 ("undernourished or 16-sib litters") [10]. When possible the litters contained equal numbers of males and females. The six dams used were provided with unlimited food [29] and water. The pups were weaned at 21 days and placed two to a cage [7] with unlimited food and water. The pups were weighed, and nose-rump and tail lengths measured on a measuring board with the animals relaxed under ether anesthetic [8]. On days 3, 7 , $14,21,28,35,49,63,77,91,105,119$, and 228 whole body radiographs were also taken, enabling bone lengths to be measured and an assessment of skeletal maturity to be made [9]. The experiment was continued until skeletal maturity reached $98 \%$ of the adult value in both groups.

The means and SD of each measurement at each age (distance curves) were calculated from the data available at the age in question in a cross-sectional way. The means and SD of the rate of growth (velocity curves) were calculated from the actual increments of individual animals from one examination to the next.

The $P$ values given in Results with the percentage values were obtained from tables of these values [30]. Numbers diminished only slightly. In the 8-pup group 17 animals were present at each observation time until 77 days when 14 animals were present; this number remained unchanged until the last observation at 228 days when only 13 animals were present. In the 16-pup group 17 animals were present until 35 days after which 15 were present till day 119; at the day 119 and day 228 observations 14 animals were present. In experiments of this kind, bias may be introduced by the dimunition of numbers in the later part of the experiment due to the deaths of unhealthy animals. In the period before death such animals are likely to grow less than normal, causing the mean growth curve to be depressed before they die and elevated after their death. The bias is less in actual-increment velocities, although still present [22]. This bias was avoided by excluding all data from the three animals who died in this way. The dimunition of numbers occurring during the experiments is due to anesthetic deaths or to poor positioning resulting in unusable radiographs.

As regards the figures, a purely illustrational difficulty arises in plotting velocity which does not occur in plotting distance. Each distance plot represents a measurement taken at a particular point on the time axis, but each velocity represents only the average velocity over the whole time elapsed between successive measurements. The velocities are therefore plotted at midpoint of the period over which they were measured. This produces an apparent ambiguity when weaning occurs, as the effect may seem to begin before weaning itself takes place. Actually, the effect of weaning is visible as the difference between the velocity in the 1421-day period and the 21-28-day period and a horizontal bar has been placed on the charts at the first postweaning period to emphasize the point.

\section{Results}

\section{Body Weight [30] (Fig. 1)}

At 21 days the undernourished were only $60 \%(P<$ $0.001)$ of the weight of the normals. After weaning, and hence during rehabilitation, the difference between the groups progressively diminished, the undernourished being $65 \%$ of the normals at 28 days $(P<0.001), 72 \%$ at 35 days $(P<0.001)$, and $90 \%$ at 119 days $(P<$ 


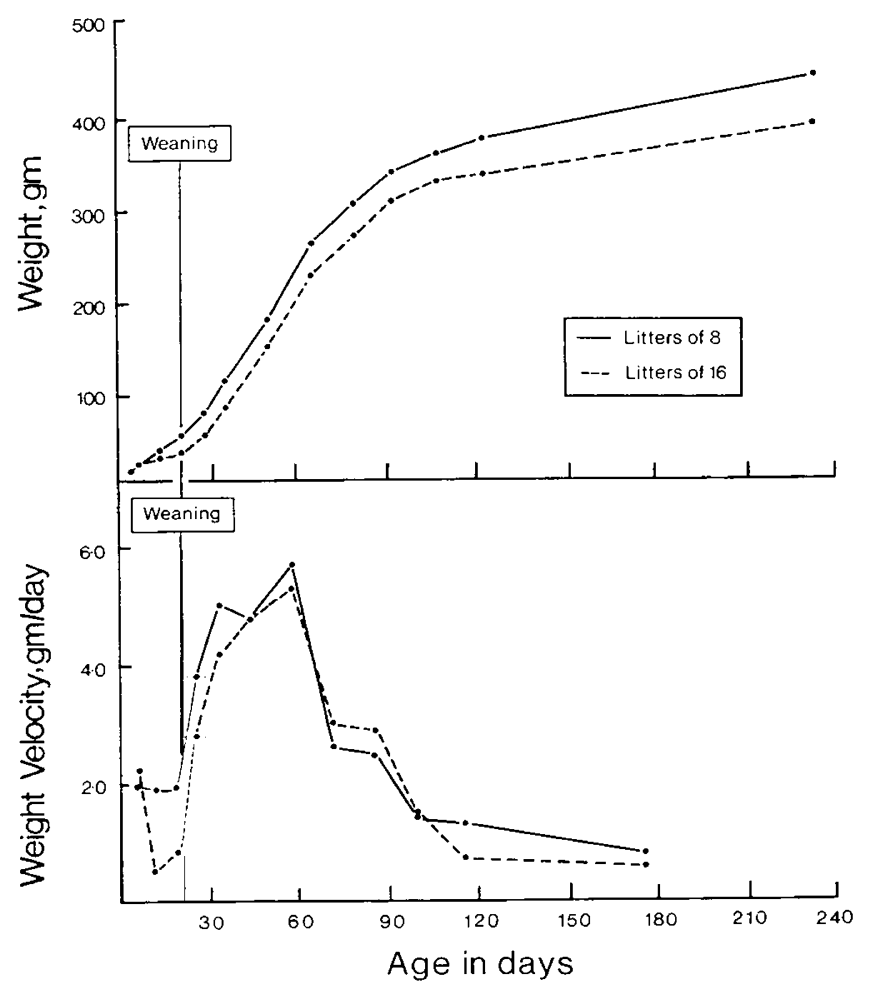

Fig. 1. Distance (upper) and velocity (lower) curves for the body weight of male rats reared in litters of 8 and 16 pups. The points on the velocity curve are plotted at the midpoint of the time period for which the velocity was calculated. The horizontal bars indicate the first velocity period after weaning.

0.05). The ultimate difference, however, at 228 days, when bone maturity was $98 \%$ of the adult value, remained significant with undernourished $88 \%(P<$ $0.001)$ of the normals; the catch-up was not complete. Both groups had a marked increase of velocity after weaning, which rose to a peak around 55 days. During this period the undernourished still grew at an absolutely slower rate than the well nourished animals: therefore, in relation to age, they did not show a catchup in weight during this time. In relation to their body weight, however, they were indeed growing faster than normals; their 28-49-day rate being $19 \%$ of their weight at 28 days, compared with the value for normals of $14 \%$.

\section{Nose-Rump Length [30] (Fig. 2)}

At weaning, the undernourished were only $87 \%$ $(P<0.001)$ of the length of the normals, and at 28 days, despite 7 days of rehabilitation, they had further sunk to $85 \%(P<0.001)$. Thereafter, their velocity equalled or exceeded that of the normals, so that by
35 days they were $90 \%(P<0.001)$ as long, by 63 days $97 \%$ as long, and by 120 days $98 \%$ as long, with a difference that was no longer statistically significant. Catch-up in body length was apparently complete. The velocity curves showed that a catch-up velocity occurred, but not immediately after rehabilitation commenced. The first velocity after weaning failed to reach the velocity of the normals, but the next point, at 2835 days, was well above the normals.

\section{Tail Length [30] (Fig. 3)}

By the time of weaning the tail length of the undernourished was $87 \%(P<0.001)$ of the normals. The velocity of the undernourished animals failed to increase immediately after weaning and at 28 days the mean for the undernourished animals had fallen to $80 \%(P<0.001)$ of normal compared with $85 \%$ for body length. Thereafter, the same sort of catch-up occurred as for body length. However, the extent of the catch-up was less than for body length and by the end of the growth period the undernourished animals still had significantly shorter $(P<0.05)$ tails than the normal animals, finally averaging $97 \%$.

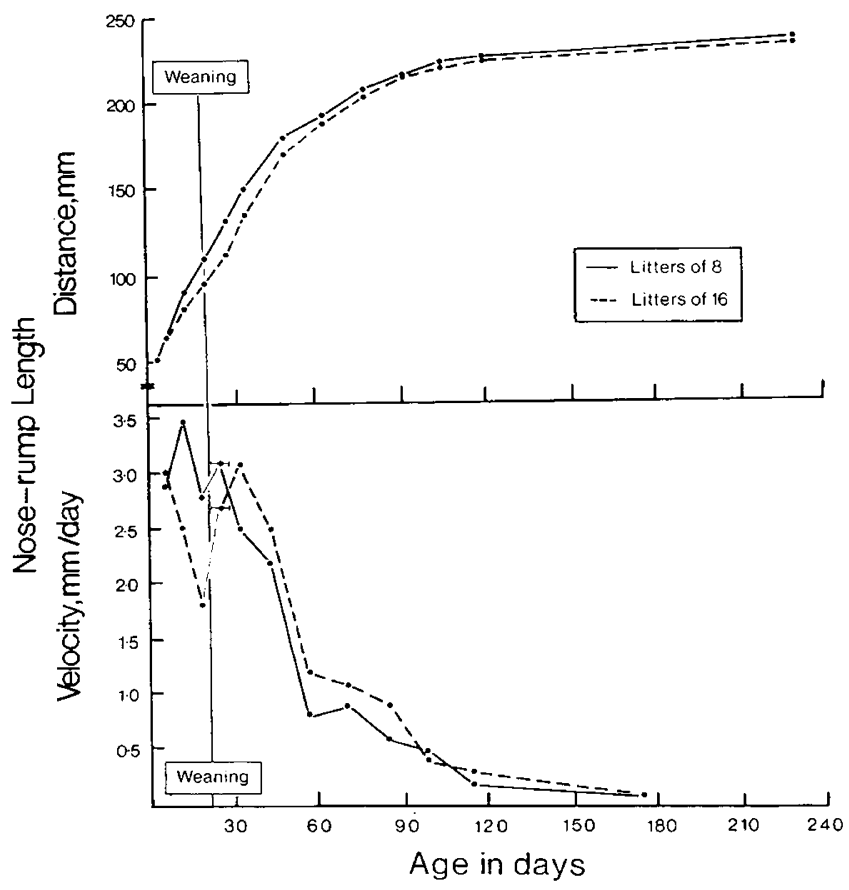

Fig. 2. Distance (upper) and velocity (lower) curves for the noserump length of male rats reared in litters of 8 and 16 pups. The points on the velocity curve are plotted at the midpoint of the time period for which the velocity was calculated. The horizontal bars indicate the first velocity period after weaning. 


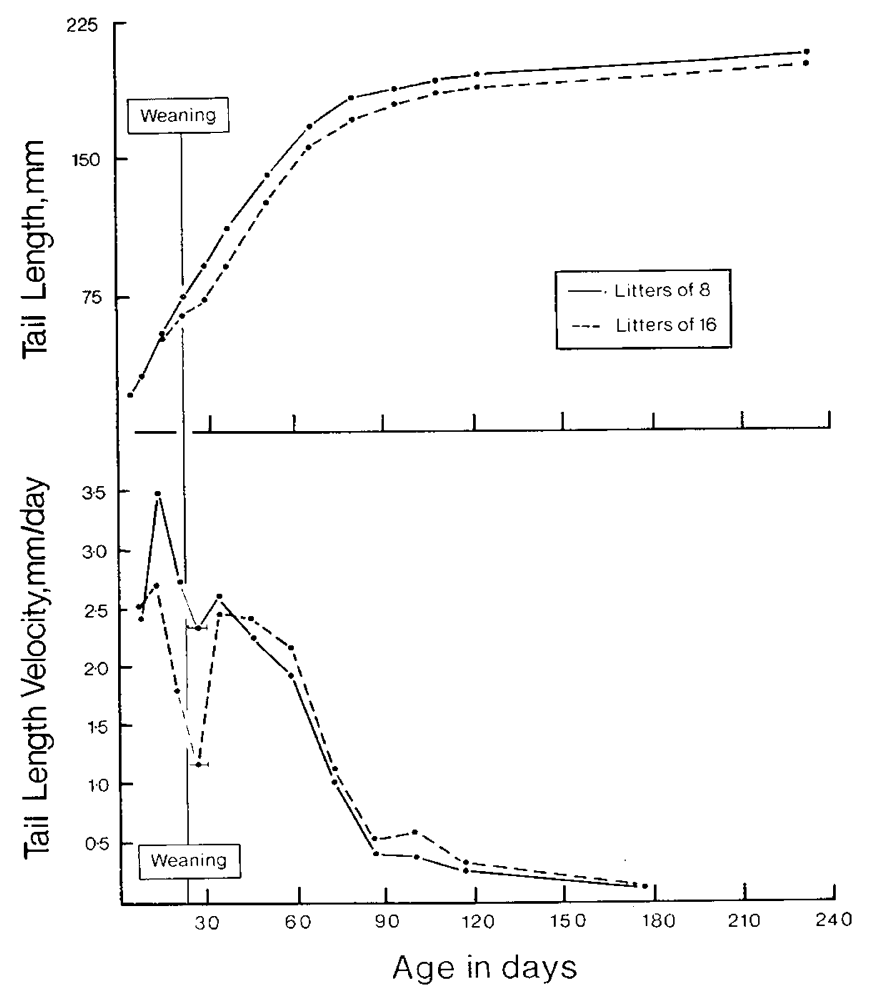

Fig. 3. Distance (upper) and velocity (lower) curves for the tail length of male rats reared in litters of 8 and 16 pups. The points on the velocity curve are plotted at the midpoint of the time period for which the velocity was calculated. The horizontal bars indicate the first velocity period after weaning.

\section{Skeletal maturity [30] (Fig. 4)}

By 14 days the score for the undernourished animals had fallen behind the normals by an amount corresponding to about a day's growth. After weaning, the undernourished group fell still further behind at 28 days being some 5 days' retarded $(P<0.001)$ and at 35 days even more. Only after 35 days did the undernourished animals begin to overtake the normals as the latter's increments in score diminished. Skeletal maturity is unlike a body measurement, in that both groups must necessarily end with the same adult score, whatever the body size. Thus we cannot talk about catch-up in the same sense as for weight or length.

\section{Weight and Lengths for Skeletal Maturity (Fig. 5)}

Figure 5 shows weight, nose-rump, and tail lengths plotted, not against age, but against skeletal maturity score.

\section{Discussion}

Our results make it clear that in studying the completeness or otherwise of catch-up, an arbitrary experimen- tal end-point is not satisfactory. The natural end-point would be total cessation of growth, but this occurs in male hooded rats only after 400 days, and changes in the last 200 days are very small. We selected the end-point by reference to maturation of the skeleton, because we have a clear definition of this, choosing $98 \%$ of the adult bone maturation score [9]. At this time the weight velocity was less than $0.5 \mathrm{~g} /$ day and the noserump length velocity less than $0.05 \mathrm{~mm} /$ day. This technique avoids the problems introduced by the separation of chronologic and developmental "ages" (i.e., growth delay) in the undernourished as compared with the normals.

The number of pups in the "control" litters is also a matter for careful decision. We have chosen eight because this is as recommended by Porter [19] for laboratory-reared rats [19]. Many previous authors (e.g., see References 8,11 , and 25) have used litters of three or four; hence their controls are overnourished compared with our "normal" animals, and the results must be interpreted with this in mind. The general

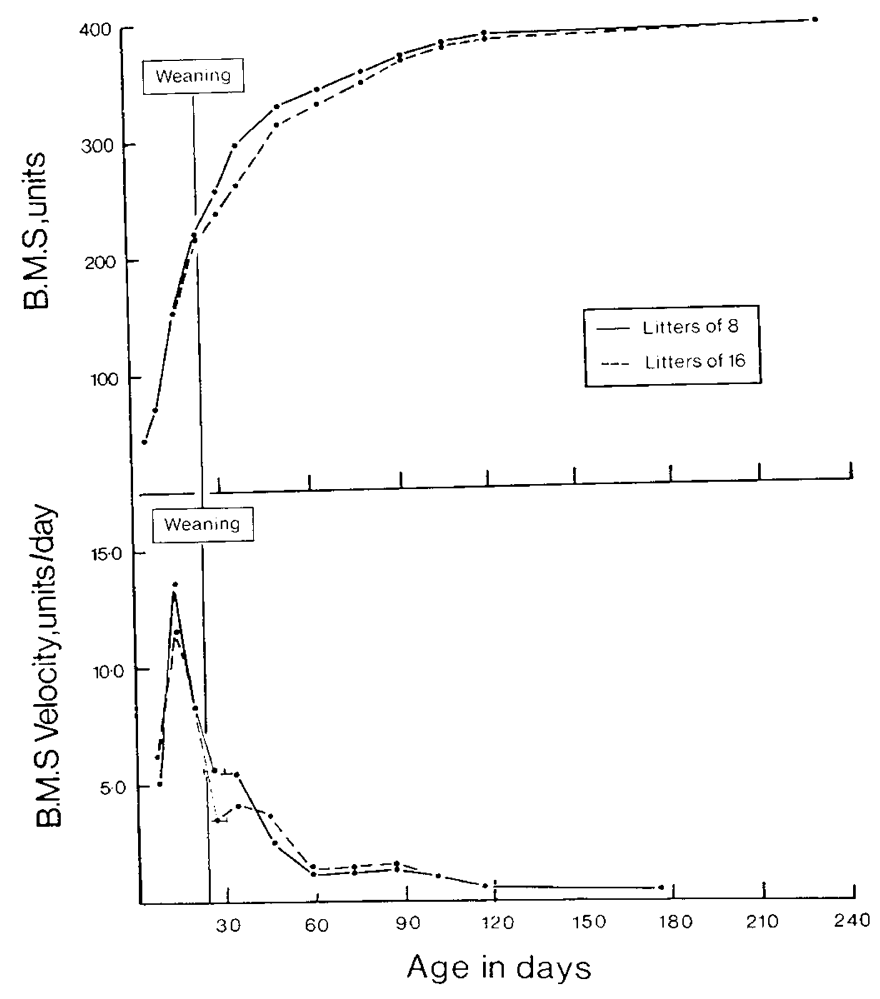

Fig. 4. Distance (upper) and velocity (lower) curves for the bone maturity score (B.M.S.) of male rats reared in litters of 8 and 16 pups. The points on the velocity curve are plotted at the midpoint of the time period for which the velocity was calculated. The horizontal bars indicate the first velocity period after weaning. 


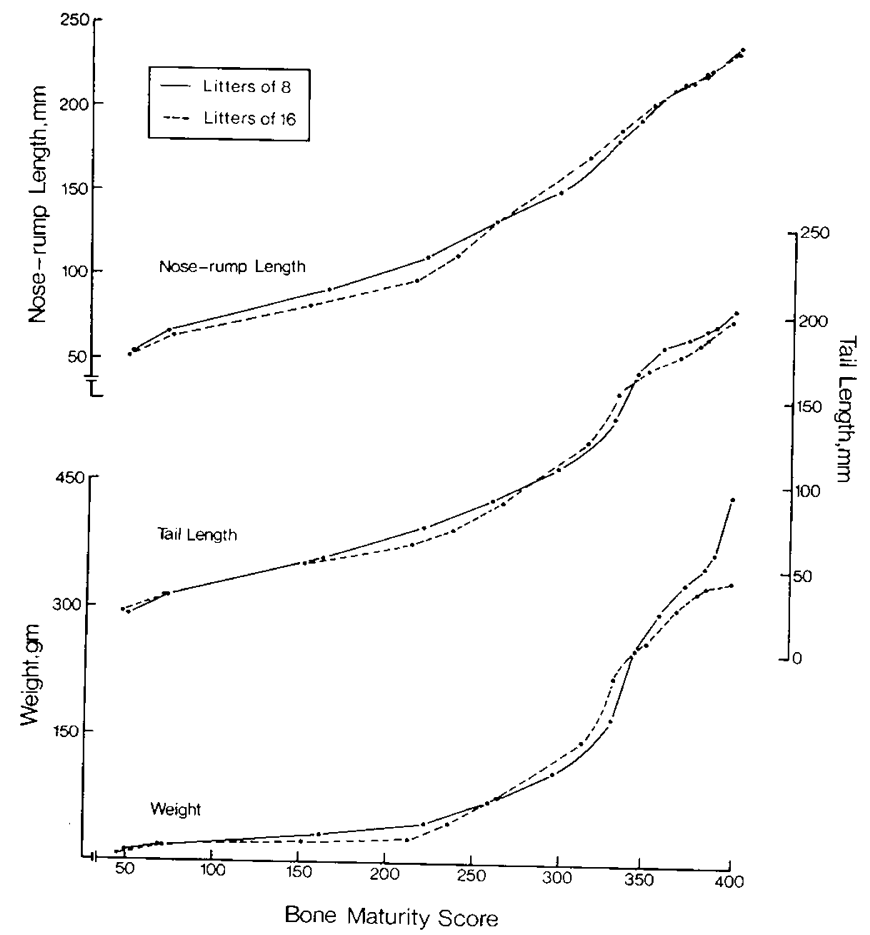

Fig. 5. Growth variables plotted against bone maturity score for male rats reared in litters of 8 and 16 pups.

title of Widdowson and McCance's classic series of papers is "Some effects of accelerated growth" (our italics).

Growth during the suckling period is determined by nest conditions, including milk supply [1]. The smaller size at weaning of animals reared in large litters is attributed to the inability of the dam to produce adequate amounts of milk [12]. Milk production in the rat reaches a peak at 10 days [17]. From 3 to 7 days there is little difference in the growth rates of the 8-sib and 16-sib groups, but from 7 to 14 days large differences in velocity appear, except in tail length, which only begins to be affected in the 14-21-day period.

At 21 days the pups were weaned and given access to unlimited food and placed two to a cage. Growth velocities increased immediately in nose-rump and body weight but a short delay was seen in tail length.

Apart from the direct effects of undernutrition the only major difference in the overall growth pattern was seen in the second peak of the nose-rump length velocity curve. In the undernourished animals the decline of the growth velocity normally occurring at 28 days was delayed and this accounts for the catch-up occurring in the variable.

The plot of nose-rump length and weight against bone maturity score (Fig. 5) indicates that at weaning (a score of 222 in the normal and 212 in the undernourished groups), the normals were longer even for their maturity score. The difference in size was therefore not solely due to slowing down of development in the undernourished, for if this were so the two groups would be equal in size at equal maturity scores.

In fact, the two groups did become equal in weight and lengths for maturity at a score of about 260 , which corresponds to about 28 days in normals and 35 days in the undernourished. From 35 days to about 75 days the undernourished were suffering primarily from a delay in growth and were in correct size maturity proportion but delayed on their time path. This delay might be expected to be made good eventually, and the top curve of Figure 5 shows that for the nose-rump length this expectation was fulfilled; after the bone maturity score of 340 the two groups proceed together. But in weight something else happened; after the 340 score the normals increased their weight for given bone maturity relative to the undernourished and at the very end of the growth period did so markedly. This probably indicates that the final weight deficit of the undernourished is not due to deficit in the skeleton but in some other tissue.

In weight the undernourished at no time looked as though they would catch up with the normals. Their velocity remained below that of the normals during the whole of the weight velocity increase and only exceeded the normals briefly and insignificantly from 60-90 days. From 90-105 days the velocities of the two groups were about equal but from 105 onwards the normals put on considerably more weight than the 16 pup/litter group. By this age their skeletal maturity was practically adult and the curves of weight for skeletal maturity thereafter diverge markedly in the two groups. Thus the final weight difference is not due to a difference in skeletal growth, but to something else.

In older rats most of the weight gained is due to fat [2I]. Lesser et al. [13] reported that between days 297 and 421 their Sprague-Dawley rats increased in fat-free body weight by $22 \mathrm{~g}$ whereas the total fat increased by $70 \mathrm{~g}$. Widdowson and McCance [25] found that animals reared in 3-sib litters had 1.6 times as much fat/U body weight at 160 days (their end-point) as animals raised in large number litters.

Knittle and Hirsch [11] reported that marked differences in both fat cell number and size occurred between rats suckled in 4-sib litters and 22-sib litters. At 140 days (their last age), the undernourished had a mean body weight $70 \%$ of that of the well nourished, with the number of fat cells only $57 \%$ of the well nour- 
ished and the amount of fat per cell $59 \%$ of the well nourished.

Hollenberg and Vost [6] demonstrated that starvation reduced the proliferation of fat cells in early life in rats and later refeeding failed to restimulate the proliferation despite increasing the size of existing cells. Brook [3] has recently suggested that in man there is a period extending from the last part of the fetal period to about 1 year in which the final number of fat cells is determined. It seems, therefore, that undernutrition during the suckling period of the rat reduces little, if at all, the ability of the skeleton to effect a complete catchup in growth, but impairs the ability of the adipose organ to do likewise.

In a previous study $[7,8]$, rats of the same colony as those reported here suckled in 8-sib litters, were followed till 200 days. At this time their mean weight was only $82 \%$ of that of the 8 -sib rats of the present study (a significant difference) but their nose-rump length was $99 \%$ and their tail lengths $98 \%$ of the present normals. With respect to our normals in the present experiment they behaved like undernourished, then rehabilitated rats. In the earlier study the animals were deliberately allowed to wean themselves ad lib rather than being suddenly removed from the dam in the usual laboratory way. Complete weaning only occurred at 35 days. During the 21-35-day period, therefore, they were probably undernourished compared with our present 8-sib animals and certainly lived in overcrowded conditions $[7,20]$, with 8 animals plus the mother to a cage. The comparison between this earlier study and the present one therefore may imply that the critical period for the rat adipose organ extends a little beyond the usual weaning time of 21 days, to at least 35 days. It probably ceases soon after, for Hirsch and Han [5] showed that starving rats from day 42 to day 49 did not impair the capacity of the fat cells to achieve the usual adult number after rehabilitation.

\section{Summary}

Male rats have been undernourished from birth to weaning by being placed in 16-pup litters, compared with "normal" litters of 8 pups, then rehabilitated on unlimited food. Body weight, nose-rump and tail lengths, and bone maturity have been followed longitudinally until bone maturity was $98 \%$ complete and growth velocity reached practically zero.

At the end of growth the undernourished were only $88 \%$ of the weight of the normals, this difference being significant $(P<0.001)$. In nose-rump length, however, they had caught up to $98 \%$ of the normals, the $2 \%$ difference not being statistically signficant. In tail length they reached $97 \%$ of the normals $(P<0.05)$. Reasons are given for thinking that the failure of the undernourished group to catch up in weight was due to underdevelopment of the adipose organ.

\section{References and Notes}

1. Barnet, S. A., AND NeIL, A. C.: Growth and reproduction of mice cross-fostered between parents reared at different temperatures. J. Physiol., 215: 655 (1971).

2. Bohman, V. R.: Compensatory growth in beef cattle. The effect of hay maturity. J. Anim. Sci., 14: 249 (1955).

3. Вroок, C. G. D.: Evidence for a sensitive period in adipose cell replication. Lancet, $i i$ : 624 (1972).

4. Goss, R. J.: Adaptive Growth (Logos, London, 1964).

5. Hirsch, J., and Han, P. W.: Cellularity of rat adipose tissue: Effects of growth, starvation and obesity. J. Lipid Res., 10: 77 (1969).

6. Hollenberg, C. H., And Vost, A.: Nutritional and hormonal regulation of DNA synthesis in rat adipose tissue. Hormone Metabol. Res., Suppl. 2, 125 (1970).

7. Hughes, P. C. R., and Nowak, M.: The effect of the number of animals per cage on the growth of the rat. Lab. Anim., 7: 293 (1973).

8. Hughes, P. C. R., and Tanner, J. M.: A longitudinal study of the growth of the black-hooded rat: Methods of measurement and rates of growth for skull, limbs, pelvis, nose-rump and tail lengths. J. Anat., 106: 349 (1970).

9. Hughes, P. C. R., And TAnner, J. M.: The assessment of skeletal maturity in the growing rat. J. Anat., 106: 371 (1970).

10. Kennedy, G. C.: The development with age of hypothalamic restraint upon the appetite of the rat. J. Endocrinol., 16: 9 (1957).

11. KnIrtle, J. L., AND Hirsch, J.: Effects of early nutrition on the development of rat epididymal fat pads: Cellularity and metabolism. J. Clin. Invest., 47: 2091 (1968).

12. Kumerasan, P., Anderson, R. P., And Turner, C. W.: Effect of litter size upon milk yield and litter weight gain in rats. Proc. Soc. Exp. Biol. Med., 126: 41 (1967).

13. Lesser, G. T., Deutch, S., AND Markofsky, J.: The rat fat-free body in middle-life: Continuing growth and histochemical changes. J. Gerontol., 25: 108 (1970).

14. MCGANCE, R. A., AND WidDowson, E. M.: Nutrition and Growth. Proc. Roy. Soc. Ser. B. Biol. Chem., 152: 326 (1962).

15. Nowinskr, W. W.: Early history of renal hypertrophy. In: W. W. Nowinski and R. J. Goss: Compensatory Renal Hypertrophy (Academic Press, New York, 1969).

16. Osborne, T. B., AND Mendel, L. B.: The resumption of growth after long continued failure to grow. J. Biol. Chem., 23: 439 (1915).

17. Park, A. W., and Nowosielski-Slepowron, B. A. J.: The effect of litter size on rat skull growth. Acta Anat., 81: 541 (1972).

18. Prader, A., Tanner, J. M., and Von Harnack, G. A.: Catch-up growth following illness or starvation. J. Paediat., 62: 646 (1963).

19. Porter, G. The Norway rat. In: A. N. Worden and W. LanePetter: The UFAW Handbook on the Care and Management of Laboratory Animals. (UFAW, London, 1957).

20. Rabasa, S. L.: Growth rate of the white rat in relation to number per cage. Physiol. Zool., 25: 98 (1952). 
21. SpRaY, C. N., ANd Widdowson, E. M.: The effect of growth and development on the composition of mammals. Brit. J. Nutr., 4: 332 (1950).

22. TANNER, J. M.: Some notes on the reporting of growth data. Hum. Biol., 23: 93 (1951).

23. Tanner, J. M.: Growth and development. In: J. O. Forfar and G. C. Arneil, Textbook of Paediatrics (Livingstone, Edinburgh, 1973).

24. WrdDowson, E. M.: Harmony of growth. Lancet, $i: 901$ (1970).

25. Widdowson, E. M., And McCance, R. A.: Some effects of accelerating growth. I. General somatic development. Proc. Roy. Soc. Ser. B, 152: 188 (1960).

26. Williams, J. P. G., Tanner, J. M., and Hughes, P. C. R.: Catch-up growth in female rats after growth retardation during the suckling period: Comparison with males. Pediat. Res., 8: 157 (1974).

27. Wilson, P. N., AND OsBorn, D. F.: Compensatory growth after undernutrition in mammals and birds. Biol. Rev., 35: 324 (1960).

28. Winick, M., AND Noble, A.: Cellular response in rats during malnutrition at various ages. J. Nutr., 89: 300 (1966).

29. Oxoid breeding diet, Oxoid, Ltd., London, England.

30. Tables showing means, sD, $P$ values, and numbers of animals for both distance and velocity measurements of all variables may be obtained on request from the authors.

31. The authors wish to thank Mr. M. Nowak for valuable technical assistance.

32. This research was supported by a grant from the Medical Research Council to Professor J. M. Tanner.

33. Requests for reprints should be addressed to: J. P. G. WILLiams, Ph.D., Department of Growth and Development, Institute of Child Health, University of London, 30 Guilford St., London WCIN IEH, England.

34. Accepted for publication October 10, 1973. 